\title{
Treatment of the Hypoplastic Variant of Chronic Endometritis: Arguments Against Antibacterial Therapy
}

DOI: $10.17691 / \mathrm{stm} 2016.8 .4 .13$

Received September 16, 2015

N.Yu. Katkova, MD, DSc, Head of the Department of Obstetrics and Gynecology ;

G.O. Grechkanyov, MD, DSc, Professor, Department of Obstetrics and Gynecology:

T.S. Kachalina, MD, DSc, Professor, Department of Obstetrics and Gynecology";

E.S. Kuptsova, Physician, Gynecology Department, Hospital No. $1^{2}$;

L.D. Andosova, MD, DSc, Professor, Department of Laboratory Diagnostics,

Faculty of Doctors' Advanced Training";

E.M. Kucher, Physician, Gynecology Department?;

I.A. Cheryomushkina, Tutor, Radiology and Radiotherapy Department, Faculty of Doctors' Advanced Training1;

O.I. Guseva, MD, DSc, Professor, Department of Obstetrics and Gynecology,

Faculty of Doctors' Advanced Training ${ }^{1}$

${ }^{1}$ Nizhny Novgorod State Medical Academy, 10/1 Minin and Pozharsky Square, Nizhny Novgorod, 603005,

Russian Federation;

${ }^{2}$ Privolgzhsky District Medical Centre of Federal Medico-Biological Agency of Russia,

2 Nizhne-Volzhskaya naberezhnaya St., Nizhny Novgorod, 603005, Russian Federation;

${ }^{3}$ Vyksa Central District Hospital, Nizhny Novgorod Region, 16/2 Krasnye Zori St., 607060, Russian Federation

The aim of the investigation was to provide a rationale for refusal from antibacterial therapy in the hypoplastic variant of chronic endometritis.

Materials and Methods. The study involved 116 patients with burdened reproductive history (infertility, miscarriage, IVF and ET failures), who were diagnosed with the hypoplastic variant of chronic endometritis after complex examination (hysteroscopy, morphology and immunohistochemistry of the endometrium). The study was carried out in two stages. At the first stage, the patients were examined and the autoimmune genesis of the disease was proved. At the second stage, the patients were divided into two groups, the main group (84 women) and the control (32 women). The patients in the control group received conventional antibiotic therapy with simultaneous administration of trophotropic medications (placenta hydrolysate Laennec, phlebotonic diosmin 600). In the main group we used no antibiotic therapy having included only immunomodulating trophotropic agents in the treatment.

Results. It was established that conventional therapy exerted no effect on the endometrial cell composition $\left(\mathrm{CD} 3^{+}, \mathrm{CD}^{+}, \mathrm{CD} 8^{+}, \mathrm{CD} 56^{+}\right)$ and humoral immunity indices. When using only immunomodulating trophotropic agents, positive tendencies were observed in normalization of the endometrial cell composition, autoimmunization indices decreased $(\mathrm{lg} G)$, the myometrium and endometrium blood supply improved, the endometrium proved to increase in thickness.

Conclusion. The hypoplastic variant of chronic endometritis is a typical autoimmune process, in which administration of antibiotics is useless. At the same time, the positive tendencies revealed while using immunomodulating trophotropic agents have demonstrated expediency of their introduction.

Key words: the hypoplastic variant of chronic endometritis; placenta hydrolysate; diosmin 600; antibiotic therapy.

At present there are two approaches to solving the problem of chronic endometritis treatment [1-4]. Some researchers consider this disease to be just an inflammatory reaction requiring administration of antibiotic therapy $[2,3,5,6]$, others look at chronic endometritis as an autoimmune process, in which using antibiotics is irrational [7-9].

However, it is beyond argument that chronic endometritis is mostly diagnosed in women with reproductive failures (habitual fetal loss, infertility, repeated IVF and ET failures), therefore, the necessity to reveal and manage the disease at the preconception period becomes a relevant objective in modern reproductive medicine $[6,10]$.

The hypoplastic variant of chronic endometritis with endometrial thickness in "the implantation window" remaining only $8 \mathrm{~mm}$ is known to present a major difficulty for restoration of the endometrium. The literature $[3,4,9]$ provides data on the attempts to restore the endometrium by introducing immunomodulators, stem cells and by means of physiotherapy $[2,5]$. The authors have studied the possibilities of managing the hypoplastic variant of chronic endometritis without antibacterial therapy.

The aim of the investigation was to assess the

For contacts: Natalia Yu. Katkova, e-mail: katkova_nu@inbox.ru 
efficacy of combined use of immunomodulators and a phlebotonic for treatment of the hypoplastic variant of chronic endometritis and to provide a rationale for refusal from antibacterial therapy.

Materials and Methods. There were examined and treated 116 patients with the hypoplastic variant of chronic endometritis, whose medical history presented reproductive failures (habitual fetal loss, infertility, repeated IVF and ET attempts). The age of the women under study amounted to 26-41 years with the mean of $31.3 \pm 4.7$ years. The diagnosis of chronic endometritis was established morphologically. To identify the variant of endometritis all the patients underwent pelvic ultrasound, Doppler imaging was applied to measure the blood flow. Besides, there was performed hysteroscopic, immunohistochemical and bacteriological examination of the endometrium, the parameters of systemic and local immunity were also assessed.

The study complies with the Declaration of Helsinki (adopted in June 1964 (Helsinki, Finland) and revised in October 2000 (Edinburgh, Scotland)) and was performed following approval by the Ethic Committee of Nizhny Novgorod State Medical Academy. Written informed consent was obtained from every patient.

The study was carried out in two stages. At the first stage, the patients underwent bacteriological examination of the uterine cavity contents, the parameters of systemic and local immunity, there were studied Doppler imaging and sonographic markers of the hypoplastic variant of chronic endometritis.

Based on the obtained data convincingly showing that the hypoplastic variant of chronic endometritis has an autoimmune origin, we refused from antibacterial therapy.

To prove out this decision and compare treatment outcomes with the results of conventional therapy the patients were divided into two groups (the second stage): the main group $(n=84)$ and the control $(n=32)$. In the main group the patients were treated for the hypoplastic variant of chronic endometritis without antibacterial therapy. Complex therapy included human placenta hydrolysate (Laennec) used as an immunomodulator simultaneously with phlebotonics (diosmin 600).

\section{Table 1}

The endometrial cell composition in patients with the hypoplastic variant of chronic endometritis (\%)

\begin{tabular}{cccc}
\hline $\begin{array}{c}\text { Immunity } \\
\text { indices }\end{array}$ & $\begin{array}{c}\text { Chronic } \\
\text { endometritis }(n=116)\end{array}$ & $\begin{array}{c}\text { Normative } \\
\text { values* }\end{array}$ & $\mathbf{p}$ \\
\hline $\mathrm{CD}^{*}$ & $40.3 \pm 4.2$ & $51.3 \pm 3.2$ & 0.016 \\
\hline $\mathrm{CD}^{+}$ & $14.3 \pm 2.8$ & $21.4 \pm 3.7$ & 0.031 \\
\hline $\mathrm{CD}^{+}$ & $15.7 \pm 2.5$ & $22.8 \pm 1.6$ & 0.04 \\
\hline $\mathrm{CD}^{+} 6^{+}$ & $18.6 \pm 0.4$ & $9.4 \pm 2.3$ & 0.0001 \\
\hline
\end{tabular}

* Normative values are taken from the previous studies by Katkova [11] and Mikhnina [1].
Laennec was administered in the dose of $4 \mathrm{ml}$ in $200 \mathrm{ml}$ of normal saline solution by intravenous drop infusion once in 2 days, the treatment course consisting of 10 infusions. Diosmin 600 (Phlebodia 600) was used according to the conventional scheme: $1,200 \mathrm{mg}$ per day orally for 21 days.

The control group comprised 32 women with the hypoplastic variant of chronic endometritis, who received conventional antibiotic therapy and phlebotonics (diosmin $600)$.

On completing the therapy, the endometrial cell composition $\left(\mathrm{CD}^{+}, \mathrm{CD}^{+}, \mathrm{CD}^{+}, \mathrm{CD}^{+} 6^{+}\right)$, the uterine blood flow, humoral immunity ( $\lg A, \lg G, \lg M)$ and ultrasound indices in M-mode were evaluated.

The obtained data were statistically processed using applied software Microsoft Excel with calculating the arithmetic mean $\mathrm{M}$ and standard error of mean $\mathrm{m}$. The significance of differences in compared series was evaluated using Student's t-test and accepted at 5\% significance level.

Results and Discussion. At the first stage all obtained findings were analyzed. Bacteriological examination of the uterine cavity contents of all patients with chronic endometritis revealed that only $2.4 \%$ of samples were positive for bacteria, while $97.6 \%$ of samples appeared to be sterile. Our findings are completely consistent with the research data obtained by Carr et al. [8], who consider chronic endometritis to be an aseptic autoimmune inflammation.

The endometrial cell composition (Table 1) was scarce, with $\mathrm{CD}^{+}, \mathrm{CD}^{+}$and $\mathrm{CD}^{+}$content being statistically significantly reduced $(p<0.05)$ as compared to the norm. $\mathrm{CD} 6^{+}$count, though exceeding normal values, failed to reach the concentration characteristic of classic endometritis markers $(p<0.001)$. The revealed picture pointed to the absence of marked inflammatory reaction and gave evidence of an autoimmune process.

Humoral immunity indices in the hypoplastic variant of chronic endometritis confirmed the autoimmune genesis of the disease as well. Indeed, IgM and IgA quantity did not exceed normal values ( $p>0.01)$, CIC (circulating immune complex) concentration being statistically significantly higher than in the healthy $(p<0.05)$. Major

Table 2

Humoral immunity indices in patients with the hypoplastic variant of chronic endometritis

\begin{tabular}{lccc}
\hline $\begin{array}{c}\text { Immunity } \\
\text { indices }\end{array}$ & $\begin{array}{c}\text { Chronic } \\
\text { endometritis }(\mathrm{n}=116)\end{array}$ & $\begin{array}{c}\text { Normative } \\
\text { values* }\end{array}$ & $p$ \\
\hline $\operatorname{lgA}(\mathrm{g} / \mathrm{L})$ & $2.1 \pm 1.1$ & $1.9 \pm 0.8$ & 0.123 \\
\hline $\lg \mathrm{g}(\mathrm{g} / \mathrm{L})$ & $14.3 \pm 1.5$ & $8.4 \pm 1.2$ & 0.0012 \\
\hline $\lg \mathrm{g}(\mathrm{g} / \mathrm{L})$ & $2.01 \pm 0.3$ & $2.7 \pm 0.9$ & 0.211 \\
\hline $\mathrm{CIC}($ standard units) & $272.4 \pm 32.3$ & $161.9 \pm 12.1$ & 0.02 \\
\hline
\end{tabular}

* Normative values are taken from the previous studies by Katkova [11] and Mikhnina [1]. 
changes concerned IgG content that proved to be increased by $42.5 \%(p<0.05)$, which also spoke of the autoimmune character of the inflammatory process (Table 2).

Pelvic ultrasound examination on day 21-22 of the menstrual cycle revealed that endometrial thickness in all the patients was less than normative values $(p<0.05)$ and averaged $5.1 \pm 1.2 \mathrm{~mm}$. When performing Doppler imaging, failure to visualize end branches of the spiral arteries was reported in $93.4 \%$ of women from this group, which we considered pathognomonic just for the hypoplastic variant of chronic endometritis $(p<0.01)$.

Thus, given the results of all examinations performed, there was no reason to administer antibiotic therapy in this group of women. The same data conclusively showed that the first-line treatment should be that normalizing the blood flow in the myometrium and endometrium and stabilizing the immune system.

At the second stage there was made a decision to refuse from antibiotics in treatment of a number of women $(n=84)$ and compare the obtained results with the control group $(n=32)$ where conventional therapy was used. Phlebotonics diosmin 600 was used simultaneously with an immunomodulator (human placenta hydrolysate: Laennec).

The conducted treatment results showed that none of the therapy methods led to significant changes in the endometrial cell composition $(p>0.05)$, though a tendency towards increase in $\mathrm{CD}^{+}, \mathrm{CD}^{+}, \mathrm{CD}^{+}$, $\mathrm{CD}^{+} 6^{+}$(Figure 1) was noted in the main group.

Dynamics of changes in serum globulin levels (Figure 2) convincingly shows that the use of conventional treatment with antibiotics exacerbates immune suppression and leads to the autoimmune process progression. So, $\lg \mathrm{A}$ and $\lg \mathrm{M}$ concentrations decreased even more $(p=0.04)$, while IgG concentration increased by $30.8 \%(p=0.01)$ amounting to $18.7 \mathrm{~g} / \mathrm{L}$.

Endometrial thickness in the control group remained unchanged amounting to $5.2 \pm 1.2 \mathrm{~mm}$. There was observed increase in midline echo indices in women receiving placenta hydrolysate and phlebotonic diosmin 600 . At the end of the study its value equaled $7.1 \pm 0.6 \mathrm{~mm}$, however, it failed to reach reliably normal level. Similar data are presented by authors in works [10, 12], who have studied the effect of Laennec on the endometrial thickness.

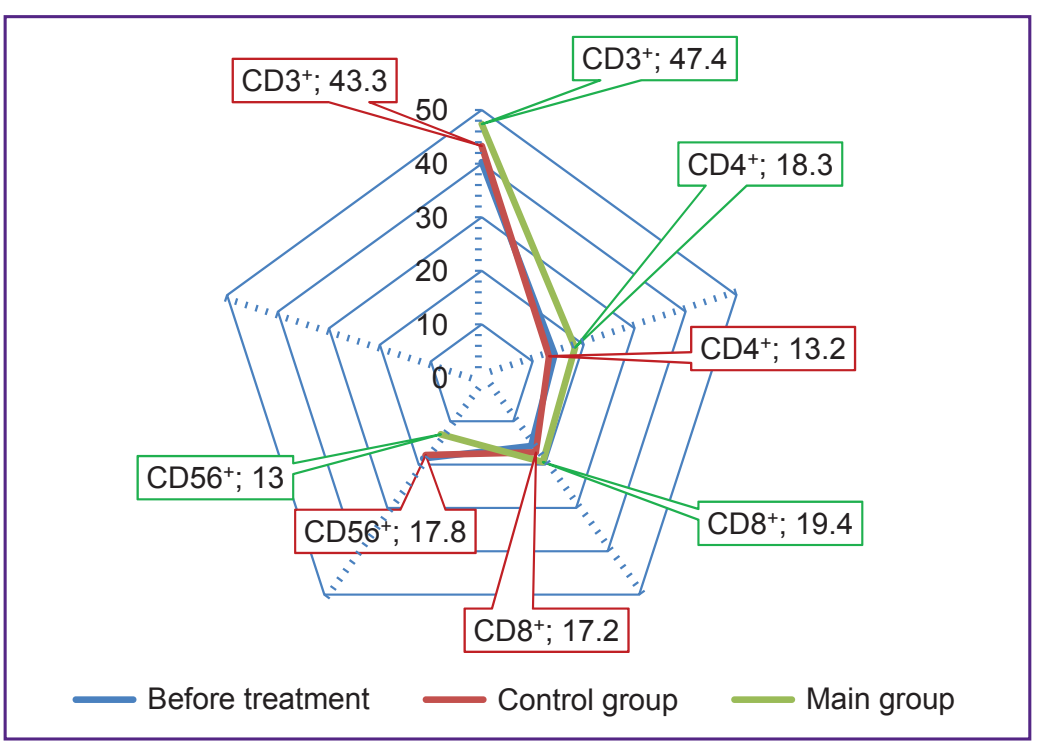

Figure 1. The influence of various therapy methods on the endometrial cell composition in patients with the hypoplastic variant of chronic endometritis

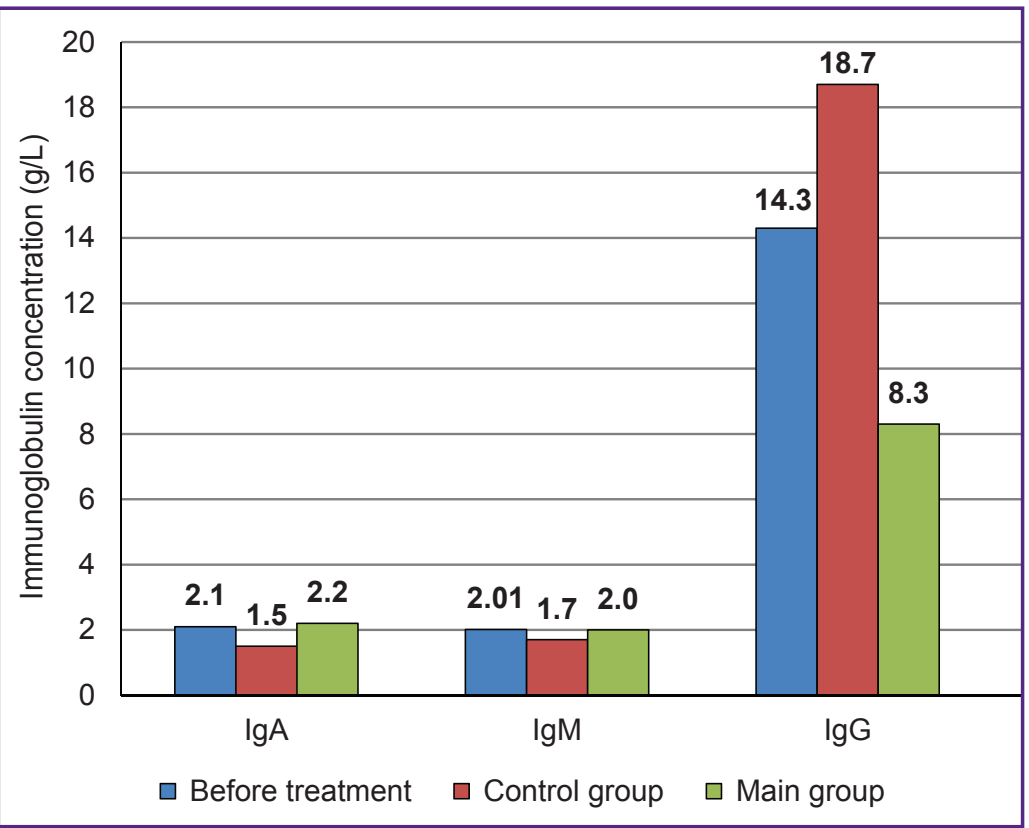

Figure 2. The influence of therapy on humoral immunity indices in patients with the hypoplastic variant of chronic endometritis

In our opinion, there were positive changes in the blood flow under the influence of the therapy in the main group. Indeed, even with initially severe damage to the endometrium and the vascular wall in the hypoplastic variant of chronic endometritis we managed to visualize end branches of the spiral arteries in 32 patients (38.1\%), this index remaining unchanged in all control patients $(p>0.05)$.

Thus, the obtained results suggest the efficacy of conducted treatment (combined use of an immunomodulator and a phlebotonic).

Conclusion. The hypoplastic variant of chronic 
endometritis is an autoimmune process which is characterized by scarcity of the endometrial cell composition, on the one hand, and autoimmunization, on the other hand.

Administration of antibiotics in the hypoplastic variant of chronic endometritis is inappropriate as antibiotics have no influence on the indices of local and systemic immunity, blood flow parameters and endometrial thickness, exacerbating, at the same time, autoimmunization of the organism.

Complex therapy of patients with the hypoplastic variant of chronic endometritis should include an immunomodulator (placenta hydrolysate Laennec) and phlebotonics (diosmin 600) due to the positive effect of this therapy on the endometrial blood supply.

Study Funding and Conflicts of Interest. The study was not supported by any financial sources, and the authors have no conflicts of interest associated with this study.

\section{References}

1. Mikhnina E.A. Morfofunktsional'noe sostoyanie endometriya $u$ zhenshchin $s$ besplodiem i nevynashivaniem beremennosti. Avtoref. dis. ... dokt. med. nauk [Morphofunctional state of the endometrium in women with infertility and miscarriage. DSc Thesis]. Saint Petersburg; 2009.

2. Shurshalina A.V., Silantyeva E.S. Possibilities of trophotropic effects on the endometrium. Ginekologiya 2012; 14(3): 50-52.

3. Di Spiezio Sardo A., Palma F., Calagna G., Zizolfi B.,
Bifulco G. Chronic endometritis. In: Genital Infections and Infertility. InTech; 2016, https://doi.org/10.5772/63023.

4. Smith M., Hagerty K.A., Skipper B., Bocklage T. Chronic endometritis: a combined histopathologic and clinical review of cases from 2002 to 2007. Int J Gynecol Pathol 2010; 29(1): 44-50, https://doi.org/10.1097/pgp.0b013e3181ae81bb.

5. Tapilskaya N.I., Karpeev S.A., Kuznetsova I.V. Subclinical inflammatory diseases of the pelvic organs: chronic endometritis. Ginekologiya 2014; 16(1): 104-109.

6. Bartlett E.C., Levison W.B., Munday P.E. Pelvic inflammatory disease. BMJ 2013; 346: f3189, https://doi. org/10.1136/bmj.f3189.

7. Graesslin O. Pelvic inflammatory diseases: guidelines for clinical practice - method and organization. J Gynecol Obstet Biol Reprod (Paris) 2012; 41(8): 833-834, https://doi. org/10.1016/j.jgyn.2012.09.013.

8. Carr B.R., Blackwell R.E., Azziz R. Essential reproductive medicine. McGraw-Hill Medical; 2015; 542 p.

9. Carp H.J.A., Selmi C., Shoenfeld Y. The autoimmune bases of infertility and pregnancy loss. J Autoimmun 2012; 38(2-3): J266-J274, https://doi.org/10.1016/j.jaut.2011.11.016.

10. Zarochentseva N.V., Arshakian A.K., Men'shikova N.S., Titchenko lu.P. Chronic endometritis: etiology, clinical presentation, diagnosis, treatment. Rossiyskiy vestnik akusheraginekologa 2013; 13(5): 21-27.

11. Katkova N.Yu. Vedenie beremennosti i rodov pri platsentarnoy nedostatochnosti infektsionnogo geneza. Avtoref. dis. ... dokt. med. nauk [Management of pregnancy and childbirth in placental insufficiency of infectious genesis. DSc Thesis]. Moscow; 2011.

12. Kuznetsova I.V., Sheveleva T.V., Pobedinskaya O.S., Uspenskaya Y.B., Gilels A.V. The use of human placenta hydrolyzate in the treatment of insufficient endometrial proliferation. Ginekologiya 2013; 15(3): 29-32. 